\title{
The effects of truncating the angle count sampling method on the Austrian National Forest Inventory
}

\author{
Ambros Berger $^{1}$ (D) $\cdot$ Thomas Gschwantner $^{1} \cdot$ Klemens Schadauer $^{1}$ \\ Received: 1 August 2019 / Accepted: 24 November 2019 / Published online: 4 February 2020 \\ (C) The Author(s) 2019
}

\begin{abstract}
- Key message Truncating the angle count sampling plots leads to a higher stock estimate because fewer trees are missed. It also causes a higher uncertainty of the estimates.

- Context The Austrian National Forest Inventory changed its plot design to angle count sampling plots that are limited to circles of $300 \mathrm{~m}^{2}$. A fixed plot size is beneficial for multistage inventory systems.

- Aims This study aims to quantify the ensuing effects on the national forest inventory on the plot and the national level regarding stock estimates and their uncertainty along with effects on as well as of upper diameter models.

- Methods Fully surveyed large-scale plots with simulated angle count samples were used to gauge the increase of variability. The full NFI 2007/09 data set was employed to simulate truncations at different distances as well as to parameterise eight alternatives for upper diameter models and to analyse the effects on the stock estimates.

- Results There is an increase in the stock estimate because the probability of missing sample trees is reduced. The change in upper diameter models had little effect.

- Conclusion The truncation removes a source of bias, facilitates field work, and is a favourable way forward.
\end{abstract}

Keywords Angle count sampling $\cdot$ National Forest Inventory $\cdot$ Uncertainty $\cdot$ Bias $\cdot$ Standing stock estimate $\cdot$ Upper diametermodel

\section{Introduction}

Handling Editor: Jean-Michel Leban

\section{Contributions of the co-authors}

Conceptualization: Ambros Berger; Methodology: Ambros Berger; Software: Ambros Berger, Thomas Gschwantner; Validation: Ambros Berger, Thomas Gschwantner; Formal Analysis: Ambros Berger, Thomas Gschwantner; Resources: Klemens Schadauer; Data curation: Ambros Berger, Thomas Gschwantner; Writing - original draft: Ambros Berger; Writing - review \& editing: Ambros Berger, Thomas Gschwantner, Klemens Schadauer; Visualisation: Ambros Berger; Supervision: Klemens Schadauer; Project Administration: Klemens Schadauer; Funding acquisition: Klemens Schadauer

Ambros Berger

ambros.berger@bfw.gv.at

Thomas Gschwantner

thomas.gschwantner@bfw.gv.at

Klemens Schadauer

klemens.schadauer@bfw.gv.at

1 Federal Research and Training Centre for Forests, Natural Hazards and Landscape (BFW), Seckendorff-Gudent-Weg 8,

1131 Vienna, Austria
The angle count sampling (ACS, Bitterlich 1948; Bitterlich 1984; Grosenbaugh 1952) has proven to be a very quick and thus cost-efficient method to select sample trees and to estimate basal area and growing stock. Austria, Germany, and Finland introduced it into their national forest inventories (NFIs) (Gschwantner et al. 2010; Polley et al. 2010; Tomppo and Tuomainen 2010; Gschwantner et al. 2016). While in Germany and Austria, a basal area factor of 4 is used, lower basal area factors ( 2 or less, depending on the region) were employed in Finland, and for the most recent NFI, ACS was replaced by two concentric circles (Tomppo et al. 2011).

ACS is sampling proportional to size, and its distinctive characteristic is that it does not have a fixed plot size. This is not an issue for pure field inventories. But multistage inventories are increasingly used due to the improving quality, increasing processing speed, and decreasing costs of remote sensing data, specifically airborne laser scanning (ALS) and image matching of aerial photos. They are incorporated into NFIs because they can greatly improve the precision of large area forest attribute estimators (Næsset et al. 2013). Several 
studies about combining ACS with ALS were carried out, e.g. in Austria (Hollaus et al. 2007; Hollaus et al. 2009), Italy (Scrinzi et al. 2015), and Finland (Maltamo et al. 2007). In order to accurately combine remote sensing data with field data, both data sets should refer to the same area (Vauhkonen et al. 2014; Tomppo et al. 2016). In other words, a fixed and clearly defined area is very beneficial. Otherwise, large trees that are outside the remote sensing window associated with the field plot could still be part of the field plot. Conversely, if the remote sensing window is chosen too large, it will contain crowns of trees that are not part of the field sample. In both cases, there is a mismatch between remote sensing data and field data which decreases the model quality.

Additionally, the truncation reduces errors caused by unobserved sample trees (Tomppo and Tuomainen 2010). Packard and Radtke (2007) investigated the statistical properties of a sampling methodology that combines fixed-radius plots with angle count sampling, and they carried out a case study on data from North Carolina, USA. Only five large-scale plots were available and tree height information was not included, so they had to rely on models for sound timber stock estimations. Yet they came to the conclusion that the combination was a promising approach.

Stage and Rennie (1994) already anticipated that 'a combination of both fixed- and variable-radius plot systems may result in the most effective inventory'. They also warned about the probability of missing sample trees and increased sampling effort with 'unbounded' plots. The reduced sample also reduces sampling time and thus costs. Particularly trees that are located further from the plot centre take longer to be measured, especially in rough terrain. For these reasons, it was decided to change the sampling design of the Austrian NFI by introducing a maximum distance of $9.77 \mathrm{~m}$ between plot centre and sample tree and adapting the estimation processes accordingly. The truncation results in a circular plot with a size of $300 \mathrm{~m}^{2}$.

The Austrian NFI uses also an upper diameter (at 3/ 10 of the tree height) for estimating stem volume. This measurement is difficult, time-consuming, and thus expensive which early on led to the decision to measure it on only a small fraction of the sample trees and model it for the rest. Yet, the Austrian NFI adheres to this measurement because it contains a lot of information about the shape of the stem (Pollanschütz 1974; Schieler 1988) and it has a large influence on the volume estimate of the tree stem (Berger et al. 2014). The truncation of the plots changes the training data set of these models because the trees outside the new plot boundary are removed from the sample.

This article focuses on the effects of the change in methods on countrywide NFI results. Three things were investigated:
1) How the results on the plot level differ with regard to estimate and uncertainty.

2) How the nationwide estimate is affected in total and split up by species and DBH.

3) How the changed training data set influences the upper diameter models and how that in turn alters the NFI estimate.

For multistage methods combining field inventory data with other data, separate studies will be carried out.

\section{Materials and methods}

The Austrian NFI employs the ACS method developed by Bitterlich (1948) with a basal area factor of 4 on all forest plots. The minimum DBH threshold for a tree to be included in the ACS sample is $10.5 \mathrm{~cm}$. For estimating the stem volume of the sample trees, tree species or species group-specific volume models (Gabler and Schadauer 2008) are used which were developed by Braun (1969), Pollanschütz (1974), and Schieler (1988). They require the input variables listed in Table 1.

All measurements except $\mathrm{D} 03 \mathrm{H}$ are taken on every ACS tree. The measurement of the upper diameter is time-consuming and consequently expensive. For this reason, the $\mathrm{D} 03 \mathrm{H}$ is measured only on a subsample of the sample trees. This data is then used to parameterise models for estimating the upper diameters of the remaining sample trees. For each species (or species group for rare species), the model is parameterised separately. Depending on the tree species, one of the two model types (1) or (2) is used (Gabler and Schadauer 2008):

$$
\begin{aligned}
& D 03 H_{t 2}=c_{0}+c_{1} \cdot D B H_{t 2}+c_{2} \cdot \frac{D 03 H_{t 1}}{D B H_{t 1}} \\
& D 03 H_{t 2}=c_{0}+c_{1} \cdot\left(D B H_{t 2}-\max \right)^{2}+c_{2} \cdot \frac{D 03 H_{t 1}}{D B H_{t 1}}
\end{aligned}
$$

The subscript denotes the previous ( $\mathrm{t} 1)$ and the current ( $\mathrm{t} 2)$ NFI, and the $\mathrm{c}_{\mathrm{i}}$ are coefficients determined by linear regression. $\mathrm{D} 03 \mathrm{H}_{\mathrm{t} 1}$ may be measured or modelled. The bracket in

Table 1 Measurements taken on the sample tree stems

Variable Description

\begin{tabular}{ll}
\hline DBH & Diameter at breast height $(1.3 \mathrm{~m})$ \\
$\mathrm{H}$ & Tree height \\
$\mathrm{HK}$ & $\begin{array}{c}\text { Height to the living crown base (only needed for broadleaved } \\
\text { trees) }\end{array}$ \\
D03H & Upper diameter at 3/10 of the tree height \\
\hline
\end{tabular}


Eq. (2) is equivalent to using $\mathrm{DBH}$ and $\mathrm{DBH}^{2}$ as input variables. The model

$$
D 03 H_{t 2}=c_{0}+c_{1} \cdot D B H_{t 2}+c_{2} \cdot D B H_{t 2}^{2}+c_{3} \cdot \frac{D 03 H_{t 1}}{D B H_{t 1}}
$$

yields exactly the same results as (2). The max was introduced to deal with correlation effects between $\mathrm{DBH}$ and $\mathrm{DBH}^{2}$. Since the models themselves are not the focus of this article, see Gabler and Schadauer (2008) for details.

\section{1) Large-scale plots and simulated ACS.}

In the years 2007, 2014, and 2015, a total of 33 large circular plots were surveyed. Every plot in Austria is corrected for slope, so it's the projection of a horizontal circle onto the terrain. Their locations were chosen to cover many ecoregions and the vast variety of forest conditions in Austria, including flat and steep terrain, locations with low and high altitude, old and young stands, and homogeneous and heterogeneous stands. The aim was to have at least two plots in every growth district ('Wuchsgebiet', Kilian et al. 1994). The radii of these plots range from 27 to $36 \mathrm{~m}$. For every tree with a $\mathrm{DBH} \geq$ $10.5 \mathrm{~cm}$ (which is the ACS measurement threshold), the variables in Table 1 and the tree species as well as their location on the plot were recorded. So these plots can be considered as fully surveyed. All in all, 6964 trees were registered and the recorded data allowed to calculate the growing stock per hectare for the entire plots.

Two examples for such plots are presented in Fig. 1. The small circles represent the trees' locations and DBHs. The symbols for the DBHs are to scale to each other (relative to the largest DBH) but oversized compared to the plot.

In addition to the 33 real plots, two synthetic plots with a radius of $45 \mathrm{~m}$ were created. All trees on the synthetic plots were set to Norway spruce. The first plot was chosen to be very regular, with all trees on a regular, triangular grid with a side length of $7.6 \mathrm{~m}$. The trees also had identical dimensions (DBH $=52 \mathrm{~cm}, \mathrm{H}=38 \mathrm{~m}, \mathrm{D} 03 \mathrm{H}=43 \mathrm{~cm}$ ) and thus identical bole volume. On the second plot, the trees were also all Norway spruce, but they were placed randomly, and only a loose constraint was introduced so that trees were not too close to each other. They also were assigned random sizes but with reasonable and realistic proportions.

Knowing the location and the DBH of a tree is sufficient to determine whether or not a tree is inside any given ACS. In order to analyse the reliability and variability of the ACS method, multiple simulated samples were taken on each plot. The centre points of these samples were placed far enough from the edge (distance depending on the largest DBH on the plot) in order to avoid underestimations due to border effects. The samples were taken on a square-shaped grid (side length $50 \mathrm{~cm}$ ) within a circular area concentric to the plot, resulting in between
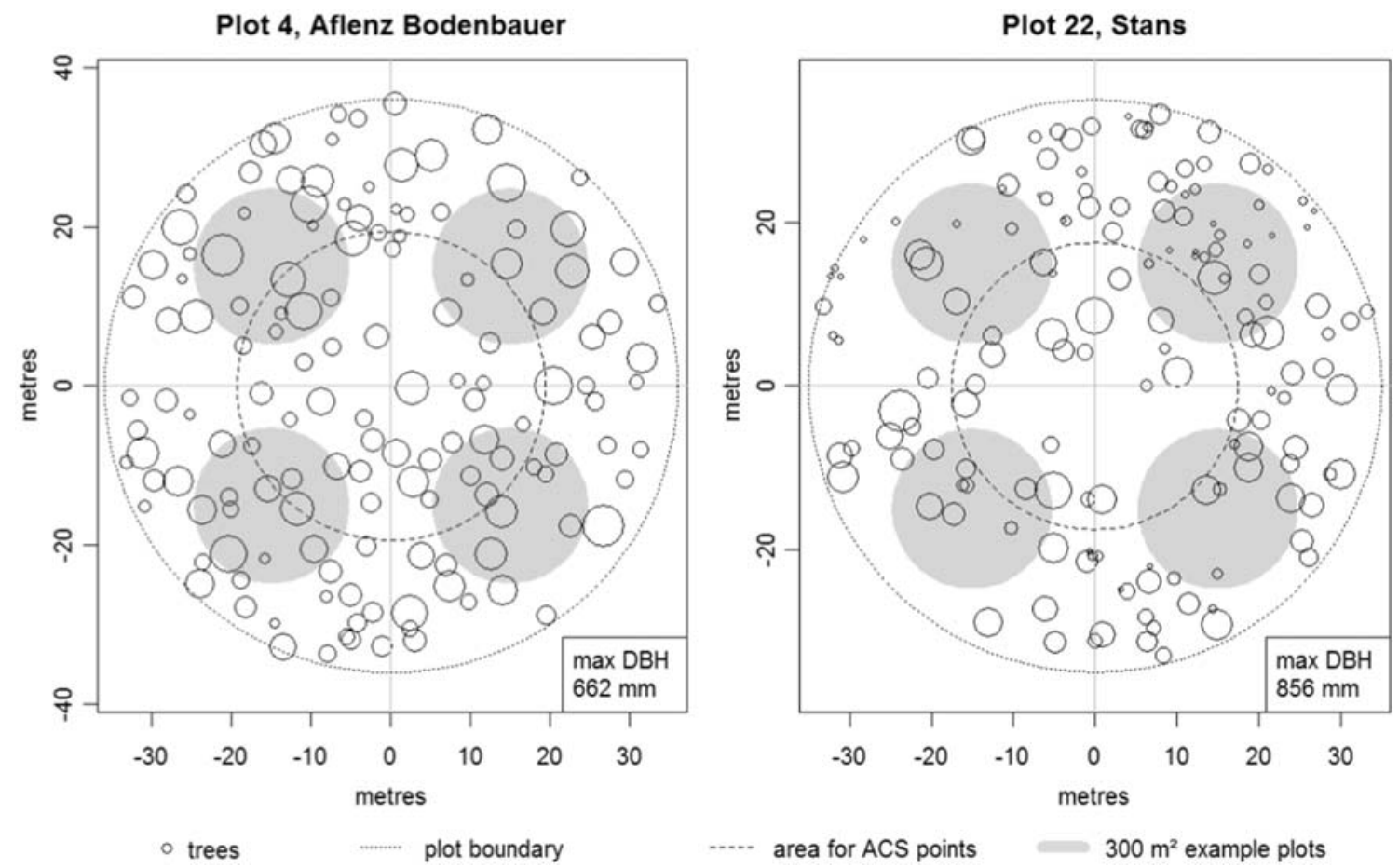

Fig. 1 Two of the 33 plots surveyed for this study showing every tree with DBH $\geq 105 \mathrm{~mm}$ (small circles), the plot boundary (dotted line), the area in which ACS sample points were located (dashed line), and four examples for $300 \mathrm{~m}^{2}$ plots (grey discs) 
2285 and 8197 samples per real plot. From the synthetic plots, 12,849 and 8577 samples were taken.

For every sample, the resulting estimate for stem volume in $\mathrm{m}^{3} /$ ha was calculated. The resulting mean was compared to the 'real' value of the plot which was obtained by using the entire area and all trees.

The same procedure was then repeated, but instead of a conventional ACS, the truncated version of the ACS was used. First these simulated ACS points were located on the exact same locations as the full ACS points for comparability purposes. But because this way the truncated samples could never contain trees that are close to the edge of the plot, in a second run, the grid was extended to include all points that were at least $9.77 \mathrm{~m}$ from the plot edge. This resulted in between 3729 and 8653 samples on the real plots and in 15,613 samples on the synthetic plots.

The mean of the ACSs is not equal to the stock per ha of the plot. This is because the plots are not completely homogenous and the area near the edge of the plots falls into fewer of the ACSs than the area near the plot centre. To compensate for this, an additional value from the field data was calculated by introducing weights. Each plot was divided into $1 \mathrm{~m}$ rings. The rings near the centre were given full weight, and the rings near the edges of the plots were assigned progressively lower weights down to almost zero for the outermost ring to better reflect the placement of the ACS points.

The minimum DBH for a tree to fall into the sample with a basal area factor 4 at a distance of $9.77 \mathrm{~m}$ is $39.08 \mathrm{~cm}$. In the Austrian NFI, the DBH is measured to the $\mathrm{mm}$. So every tree with $\mathrm{DBH} \geq 39.1 \mathrm{~cm}$ is no longer an ACS tree and thus has to be treated differently when upscaling to per hectare values. With regular ACS, a tree represents $4 \mathrm{~m}^{2}$ of basal area per ha:

$n / h a=\frac{4 m^{2}}{\left(\frac{D B H}{2}\right)^{2} \cdot \pi}$

with $\mathrm{n} / \mathrm{ha}$ being the number of represented trees per ha by each sample tree. But for trees with $\mathrm{DBH} \geq 39.1 \mathrm{~cm}$, the reference area is the fixed circle of $300 \mathrm{~m}^{2}$, and the tree instead simply represents $10,000 / 300 \sim 33.3$ trees per ha. In other words, the new plots are a combination of ACS for trees with $\mathrm{DBH} \leq 39 \mathrm{~cm}$ and fixed-radius plot for trees with $\mathrm{DBH} \geq$ $39.1 \mathrm{~cm}$. This is necessary to keep the design unbiased.

In order to compare the uncertainty of the full and the truncated ACS and their sensitivity to the exact plot location, for each plot, the standard deviation (SD) and the relative standard deviation (RSD) of the stock estimates were calculated.

\section{2) Tests on NFI data.}

In order to assess the effects of the truncation in practice, the data from the NFI period 7 were used to calculate national results for truncated ACS plots of different sizes in $50 \mathrm{~m}^{2}$ steps from $50 \mathrm{~m}^{2}$ to $1300 \mathrm{~m}^{2}$. For each plot size, the sample trees in the respective sample were upscaled to per hectare values according to the plot size.

The results for the $300 \mathrm{~m}^{2}$ plots were also analysed for different species and species groups, as well as for trees with $\mathrm{DBH}<60 \mathrm{~cm}$ and $\mathrm{DBH} \geq 60 \mathrm{~cm}$ separately, whereas for all other plot sizes, only the nationwide stock per ha was calculated.

A further effect of the truncation is an altered sample for the parameterisation of the models for the upper diameters. In particular, the sample is not thinned evenly because trees with a larger DBH are affected more strongly.

In the Austrian NFI, trees with a $\mathrm{DBH} \geq 60 \mathrm{~cm}$ are measured with a different instrument (diameter tape instead of calliper). Old and large trees also tend to have irregular stem shapes. So it was tested to treat them separately and parameterise their own model for the upper diameter. Based on the NFI 7 data set, the alternatives presented in Table 2 were tested.

The first alternative is basically what was used until the NFI 7, and alternative 6 will be used in the future. For each of the 8 alternatives, models for the upper diameters were
Table 2 List of the alternatives/ data sets for the upper diameter models evaluated in this article

\begin{tabular}{|c|c|c|c|}
\hline \multirow[t]{2}{*}{ Abbreviation } & \multicolumn{2}{|l|}{ Model parameterisation } & \multirow{2}{*}{$\begin{array}{l}\text { Volume estimation } \\
\text { Stock estimation data se }\end{array}$} \\
\hline & Training data set & $\begin{array}{l}\text { Distinction of } \mathrm{DBH}<60 \\
\text { and } \mathrm{DBH} \geq 60 \mathrm{~cm}\end{array}$ & \\
\hline 1. fnf & Full subsample & No & Full sample \\
\hline 2. $\operatorname{tnf}$ & Truncated subsample & No & Full sample \\
\hline 3. fyf & Full subsample & Yes & Full sample \\
\hline 4. tyf & Truncated subsample & Yes & Full sample \\
\hline 5. fnt & Full subsample & No & Truncated sample \\
\hline 6. tnt & Truncated subsample & No & Truncated sample \\
\hline 7. fyt & Full subsample & Yes & Truncated sample \\
\hline 8. tyt & Truncated subsample & Yes & Truncated sample \\
\hline
\end{tabular}



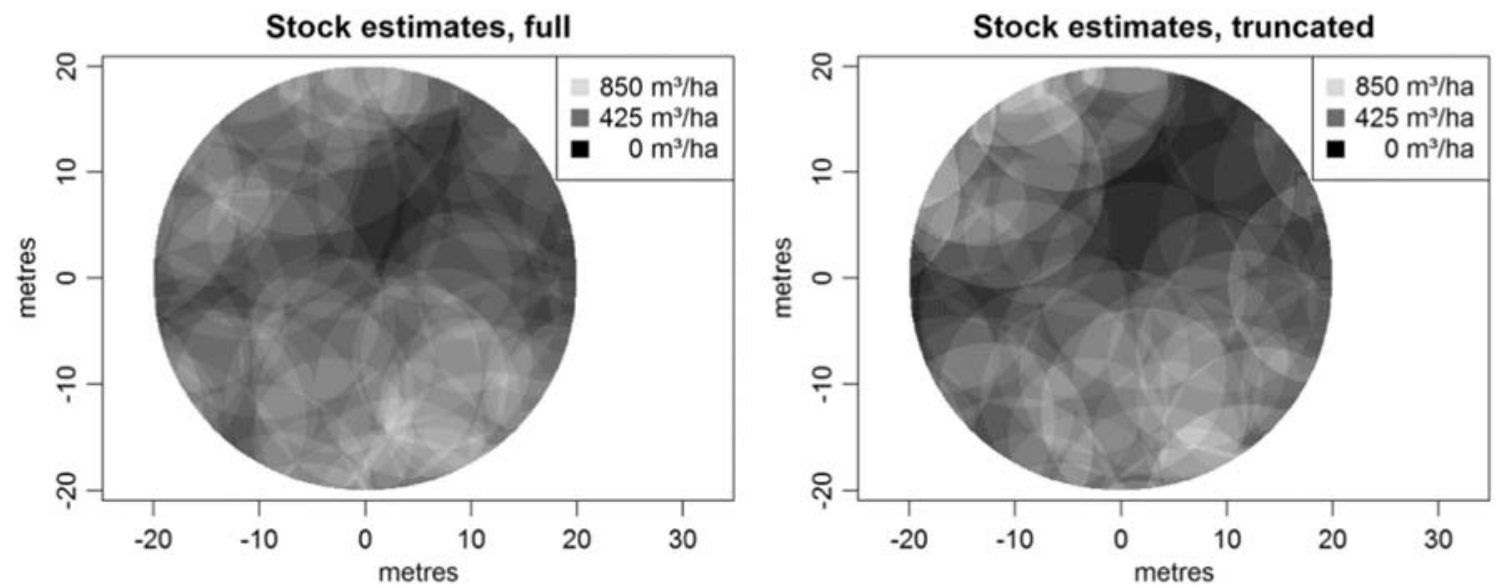

Fig. 2 Visualisation of the stock estimates for full and truncated ACS at identical locations. A lighter grey means a higher stock estimate

parameterised using the respective data set. After the parameterisation, the models were applied to the full ACS data set or the truncated ACS data set of the NFI plots, and the resulting upper diameters were compared. Finally, the resulting stock estimates and their standard errors were calculated and compared.

\section{Results}

1) Large-scale plots and simulated ACS.

The truncation of the ACS affects only trees with $\mathrm{DBH} \geq$ $39.1 \mathrm{~cm}$. Trees with a smaller DBH that are in the sample are also less than $9.77 \mathrm{~m}$ from the plot centre. This also means that plots that contain only trees with $\mathrm{DBH} \leq 39 \mathrm{~cm}$ produce the exact same results with full and truncated sampling. Figure 2 shows the results for plot 4 (the left plot in Fig. 1) for full and truncated ACS. Every pixel presents the estimated stock using that specific location as plot centre (converted to colour brightness). The displayed area is the area for ACS plots in Fig. 1. It can be seen that the truncated ACS produces a higher number of extreme values (very light and very dark areas), whereas the full ACS yields a smoother structure.

The resulting estimates for stocks for all plots are presented in Fig. 3. The 'true' values range from 100 to $1050 \mathrm{~m}^{3} / \mathrm{ha}$. Extending the grid for the truncated ACS in order to fully cover the plots mostly moved the means notably closer to the 'real' values derived from the full sample (compare + and $\times$ ). Unsurprisingly the ACS often relates better to the weighted field data, especially the non-extended truncated ACS.

The extended truncated ACSs cover the plots better but their RSDs increased slightly. The regular synthetic plot (31) produces almost identical values for all stock estimates.

The extended grid was used for the analyses of the truncated ACS samples because the better coverage of the plot was given priority over identical locations with the full ACS.
Fig. 3 Regular and weighted stocks on the plots from the field inventory and the respective means of the different ACS samples real stock and means of ACS

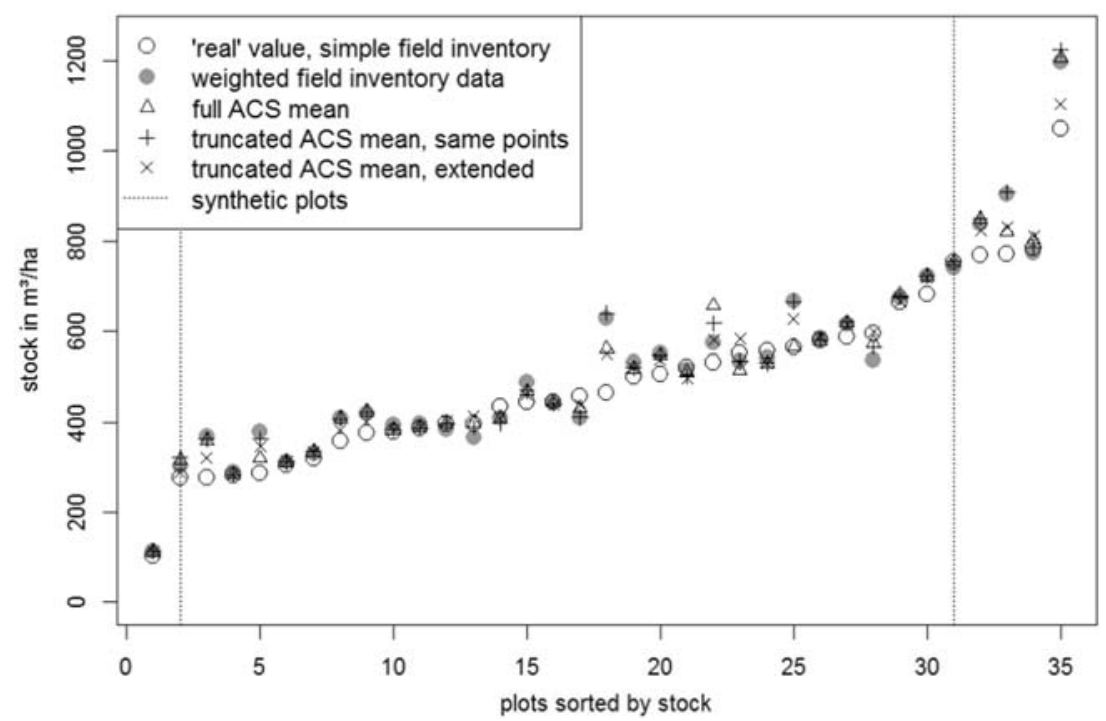


Fig. 4 Comparing the variability of the truncated angle count samples to the regular angle count samples on the real plots
Full ACS

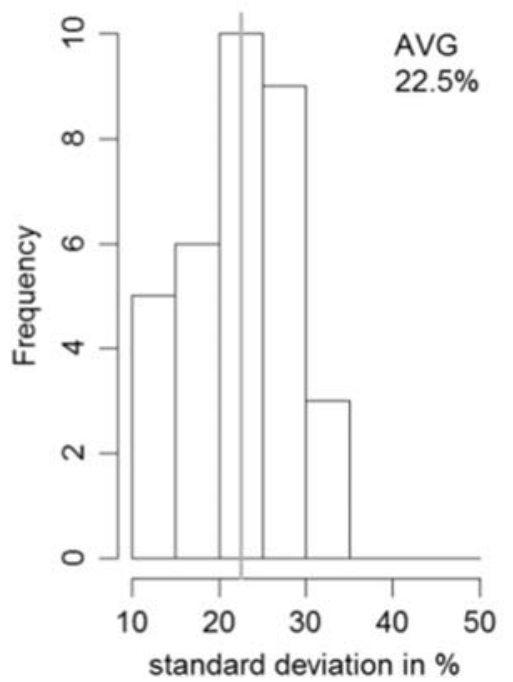

Truncated ACS

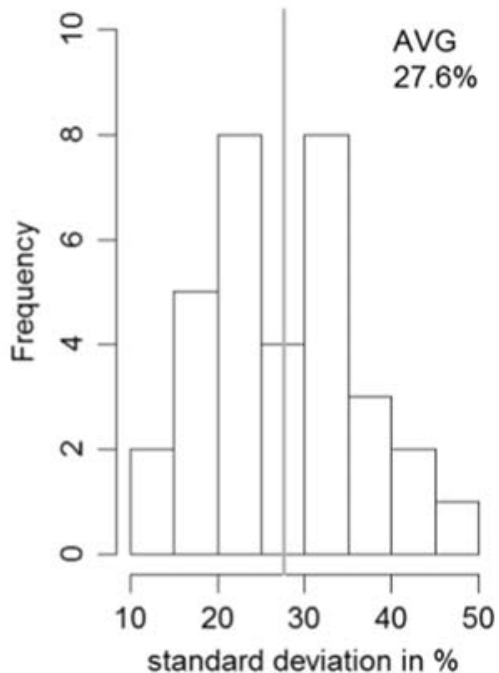

Increase of RSD due to truncating the ACS over max DBH

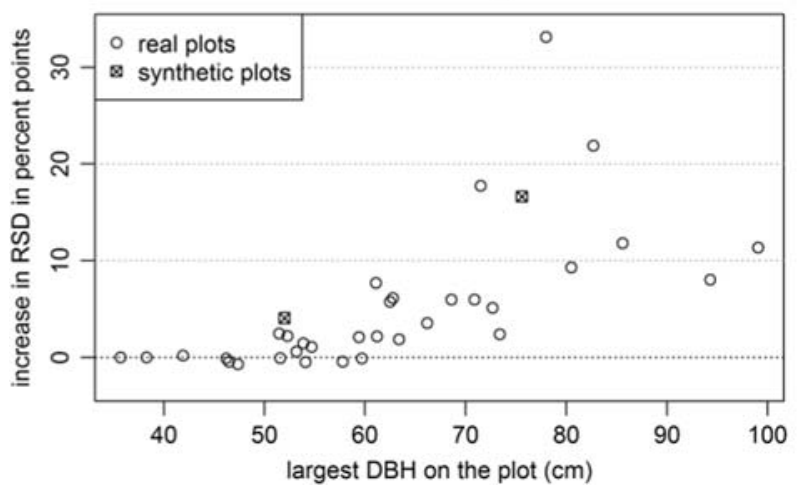

Fig. 5 The increase of the relative standard deviations due to truncating the ACS on the different plots plotted over the largest DBH of the respective plot
The RSD of the full angle count samples on one plot ranges from $12.8 \%$ to $32.9 \%$ with an average of $22.5 \%$. The truncated samples produced higher values ranging from $12.8 \%$ to $45.9 \%$ with an average of $27.6 \%$; see Fig. 4 . The regular synthetic plot resulted in $9.6 \%$ and $13.7 \%$, respectively, whereas the random synthetic plot resulted in $38.3 \%$ and $52.3 \%$.

The variability of the truncated ACS is higher than that of the full ACS on almost every plot, but this increase is rather small on most plots. The plots with a high difference in standard deviation are mostly the plots that contain at least one tree with a large DBH (above $70 \mathrm{~cm}$ ); see Fig. 5.

2) Tests on NFI data.
Fig. 6 Nationwide standing stock estimates depending on plot size with a smooth curve

\section{Standing stock depending on plot size}

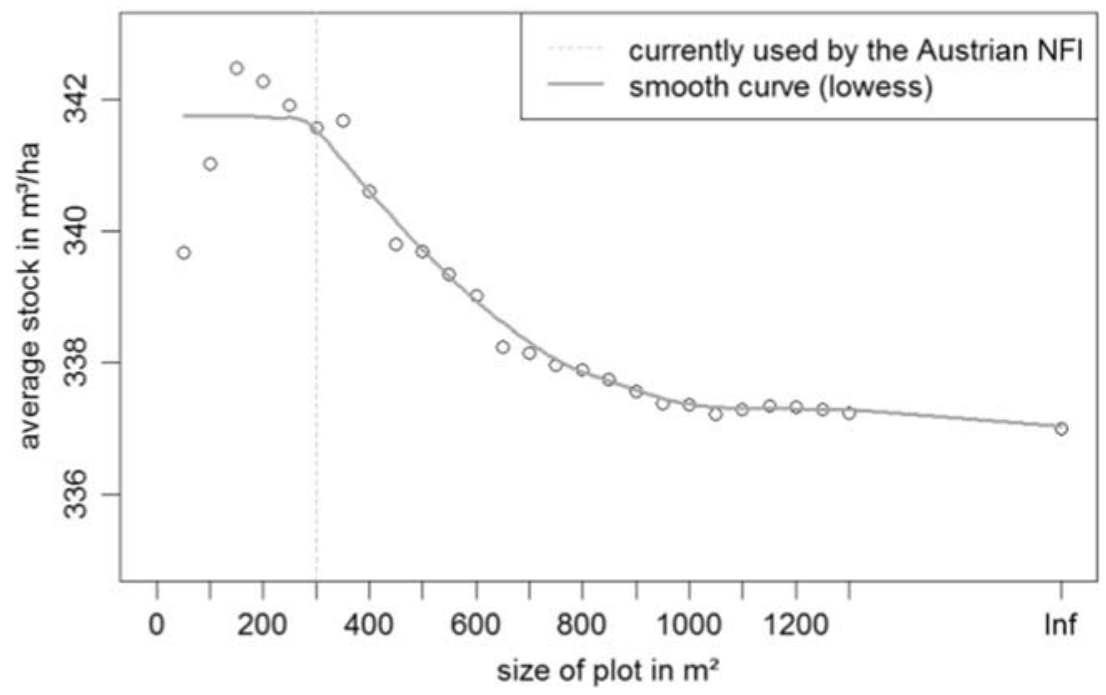


Fig. 7 Effects of the truncation by tree species and DBH class. The stock difference is calculated as estimate of the truncated method minus the estimate of the full ACS and expressed in percent of the full ACS estimate. The green line shows the share of the species (or species group) of the total stock and is scaled to the right yaxis relative differences in standing stock sorted by decreasing total standing stock

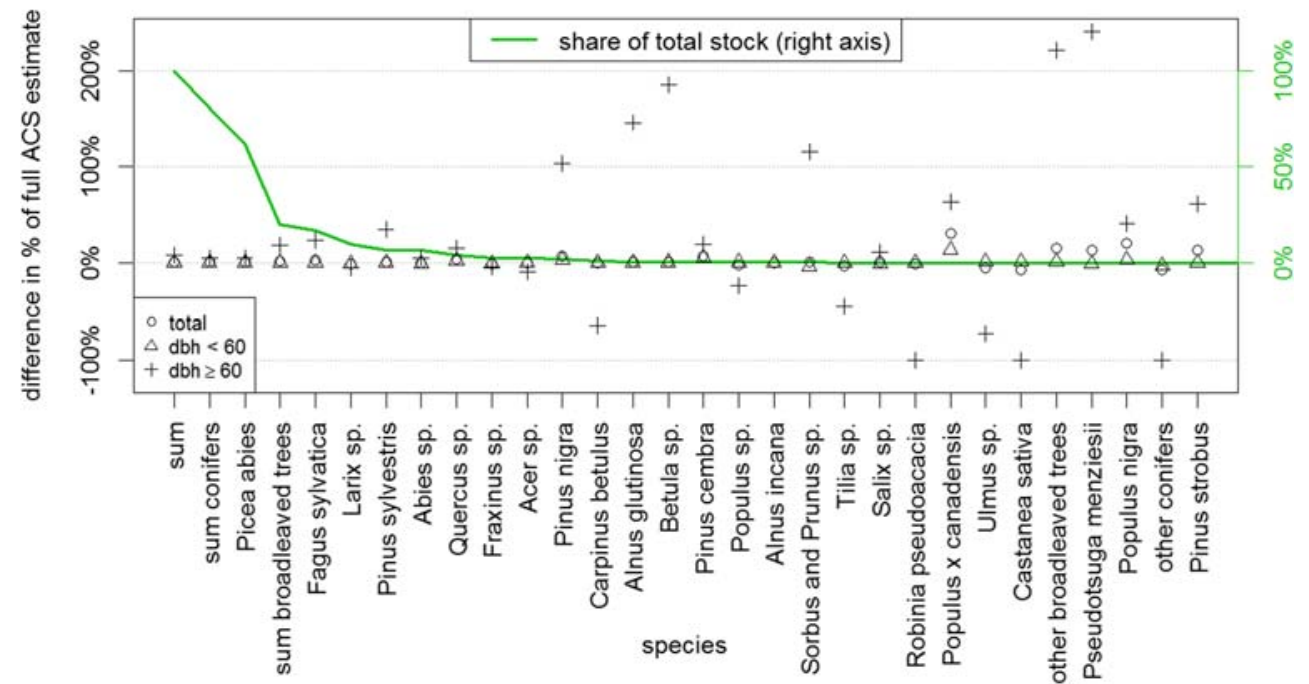

When testing the different plot sizes using NFI 7 plot data, it turned out that increasing the maximum distance for sample trees resulted in a decrease of the estimate of the overall stock, see Fig. 6, quickly at first, and then it tapers off to asymptotically approach the value for the infinite plot size which refers to the regular ACS method. The two plot sizes $50 \mathrm{~m}^{2}$ and $100 \mathrm{~m}^{2}$ are exceptions to this trend, probably due to random effects.

Looking at different species separately shows a diverse picture. For Norway spruce (Picea abies) - the by far most common tree species in Austria - the results for both the full and the truncated ACS are very similar with the estimate for total standing stock being a bit higher $(+1.2 \%)$ with the truncated ACS; see Fig. 7. The trees with $\mathrm{DBH} \geq 60 \mathrm{~cm}$ are more strongly affected.

Beech (Fagus sylvatica) and oak (Quercus) tend to have above-average DBH. Fittingly, they have a larger increase in stock due to the truncation (3.4\% and $4.5 \%$, respectively). Most of this increase comes from trees with $\mathrm{DBH} \geq 60 \mathrm{~cm}$. Larch (Larix) and fir (Abies) show only small deviations. For Scots pine (Pinus sylvestris), the stock of trees with $\mathrm{DBH} \geq$ $60 \mathrm{~cm}$ is about $35 \%$ higher in the truncated sample, but that can be attributed to the fact that most Scots pines in Austria have a smaller DBH.

Distinct random effects occur but only in tree species and tree species groups that each account for less than

\section{comparing results of $\mathrm{D} 03 \mathrm{H}$-models}

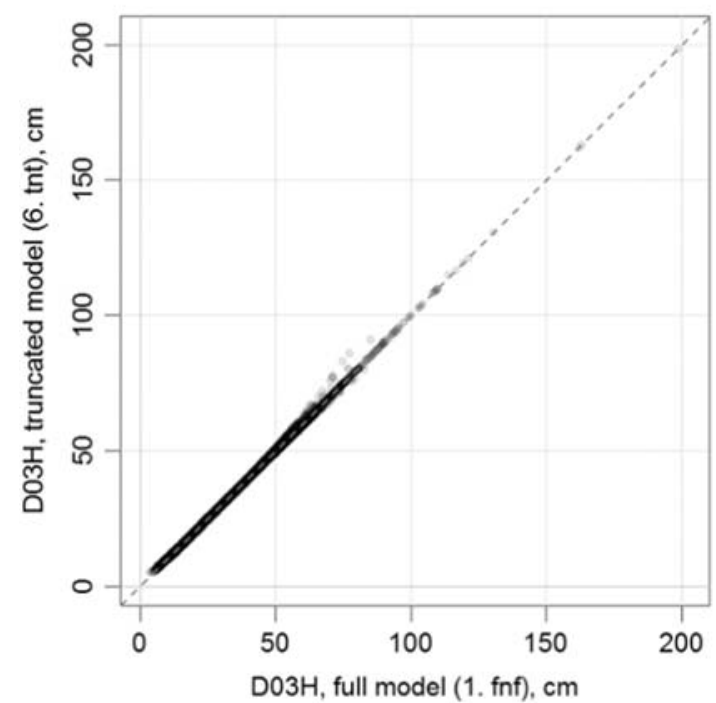

\section{comparing results of $\mathrm{D} 03 \mathrm{H}$-models}

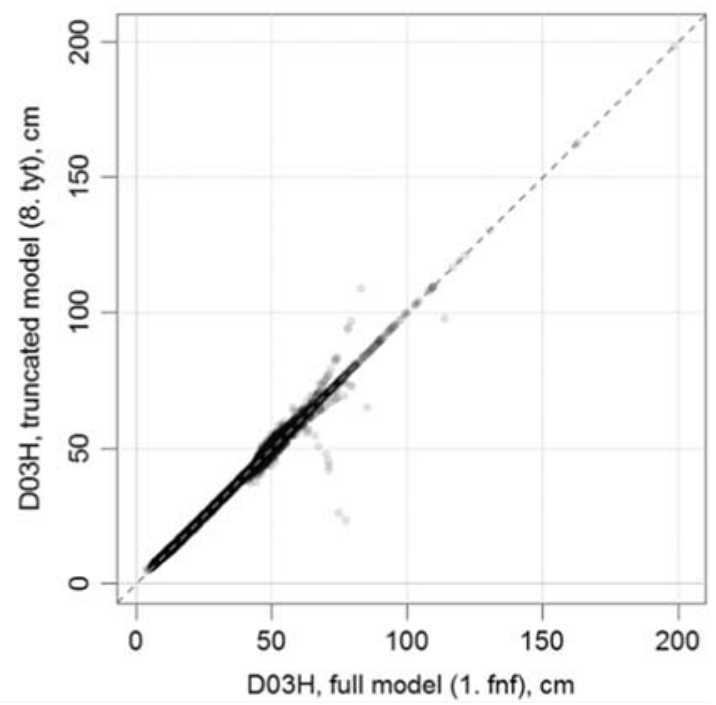

Fig. 8 Comparing the estimates of the models for D03H based on the full (1. fnf) and truncated (6. tnt left and 8 . tyt right, with separate model for DBH $\geq$ $60 \mathrm{~cm}$ ) data sets. The data points are plotted in transparent black to better visualise where the majority of the data points lie 
Table 3 Comparison of resulting stocks by upper diameter model, see Table 2 for the names

$\begin{array}{lllllllll}\begin{array}{l}\text { total estimate } \\ \mathrm{m}^{3} / \mathrm{ha}\end{array} & \begin{array}{l}\text { standard error } \\ \mathrm{m}^{3} / \mathrm{ha}\end{array} & \begin{array}{l}\text { standard error } \\ \text { percent }(\%)\end{array} & \begin{array}{l}\text { estimate for } \\ \mathrm{DBH}<60 \mathrm{~cm} \\ \mathrm{~m}^{3} / \mathrm{ha}\end{array} & \begin{array}{l}\text { standard error } \\ \mathrm{m}^{3} / \mathrm{ha}\end{array} & \begin{array}{l}\text { standard error } \\ \text { percent }(\%)\end{array} & \begin{array}{l}\text { estimate for } \\ \mathrm{DBH} \geq 60 \mathrm{~cm} \\ \mathrm{~m}^{3} / \mathrm{ha}\end{array} & \begin{array}{l}\text { standard } \\ \text { error } \mathrm{m}^{3} / \mathrm{ha}\end{array} & \begin{array}{l}\text { standard error } \\ \text { percent }(\%)\end{array} \\ 337.0 & 2.94 & 0.87 & 308.6 & 2.75 & 0.89 & 28.4 & 0.85 & 3.01 \\ 336.0 & 2.93 & 0.87 & 307.6 & 2.73 & 0.89 & 28.4 & 0.85 & 3.00 \\ 336.0 & 2.93 & 0.87 & 307.5 & 2.73 & 0.89 & 28.5 & 0.86 & 3.01 \\ 336.0 & 2.94 & 0.87 & 307.6 & 2.73 & 0.89 & 28.5 & 0.86 & 3.01 \\ 341.6 & 3.08 & 0.90 & 310.9 & 2.82 & 0.91 & 30.6 & 1.10 & 3.58 \\ 341.3 & 3.08 & 0.90 & 310.5 & 2.81 & 0.91 & 30.8 & 1.10 & 3.58 \\ 340.7 & 3.07 & 0.90 & 309.9 & 2.80 & 0.90 & 30.8 & 1.10 & 3.59 \\ 340.8 & 3.07 & 0.90 & 310.0 & 2.80 & 0.90 & 30.8 & 1.10 & 3.59\end{array}$

$1 \%$ of Austria's total standing stock. The values for trees with $\mathrm{DBH} \geq 60 \mathrm{~cm}$ range from $-100 \%$ (robinia (Robinia pseudoacacia), chestnut (Castanea sativa), and 'other conifers' losing all such trees in the sample) to $+240 \%$, with an overall tendency to a higher stock for the truncated ACS, as expected. White alders (Alnus incana) with $\mathrm{DBH} \geq 60 \mathrm{~cm}$ do not occur even in the full NFI 7 data set.

The changed data set did not cause much difference in the estimated values for D03H. Figure 8 shows that only a few values stray from the 1:1 line (dashed) when comparing the values of 1 . fnf and 6. tnt (see Table 2) on the left. These two alternatives were chosen because they stand for what was used and what will be used, respectively. Using separate models for trees with $\mathrm{DBH} \geq 60 \mathrm{~cm}$ showed more and a lot larger deviations (1. fnf vs 8 . tyt, on the right).

The different ways of calculating the upper diameter did not produce any relevant differences in the results. The only notable difference is whether the ACS is truncated or not, but within the groups 'truncated ACS' and 'full ACS', the variation between the different methods lies well within the standard error. The resulting stock per ha estimates for the full ACS ranged from 335.96 to $337.00 \mathrm{~m}^{3} / \mathrm{ha}$ with standard errors always around $2.94 \mathrm{~m}^{3} / \mathrm{ha}$, whereas the truncated ACS produced values from 340.74 to $341.57 \mathrm{~m}^{3} /$ ha with standard errors around $3.07 \mathrm{~m}^{3} / \mathrm{ha}$. That means that the standard errors increased from $0.87 \%$ to $0.90 \%$ due to the truncation.

The share of the trees with $\mathrm{DBH} \geq 60 \mathrm{~cm}$ is $8.4 \%$ for the full ACS and $9.0 \%$ for the truncated ACS in all variants. The truncation of the ACS caused the standard errors to rise from 0.85 to $1.10 \mathrm{~m}^{3} /$ ha $(3.0 \%$ to $3.6 \%)$ which is notably more than the overall increase.

The separate models for upper diameters of trees with $\mathrm{DBH} \geq 60 \mathrm{~cm}$ did not have a notable influence on the overall stock, but they did produce a few extreme and more unrealistic values on the single tree level. The results are presented in detail in Table 3.
1. to 4. are the full ACS stock estimation alternatives and 5. to 8 . are the truncated ACS stock estimation alternatives. The estimates are provided in $\mathrm{m}^{3} /$ ha for total stock and split up for trees below and above a DBH of $60 \mathrm{~cm}$. The respective standard errors are provided in $\mathrm{m}^{3} / \mathrm{ha}$ and in percent of the estimate.

\section{Discussion}

The truncation of the ACS sample plots increases the variability of plot-level volume estimates on average. This is to be expected because less data is used for each estimate. The two synthetic plots showed large differences between the full and the truncated ACS, but they are clearly neither representative nor exemplary for the Austrian forest. Instead they present the extreme situations concerning diameter distribution as well as tree location pattern on both ends of the spectrum. The theoretical differences of the two ACS methods are not as relevant in practice, as can be seen by the fact that on the real plots the differences were smaller. It is noteworthy that both synthetic plots show a markedly better performance of the full ACS compared to the truncated ACS than in the real situations despite being on opposite ends of the spectrum.

The more irregular plots show a higher increase in variability due to the truncation. The full ACS samples are more likely to even out irregularities on the plot because of the larger surveyed area, whereas the truncated samples have a higher probability to be located just between several large trees and containing none or only a few, or to contain a high number of large trees and ignoring adjacent treeless space.

It is not possible to directly draw conclusions about the uncertainty of the Austrian NFI from Fig. 4 because the growth districts have very different sizes and two plots per growth district are not sufficient to be representative. However, the expected trends and effects are generally visible.

This study assumes that all stems are perfectly circular, that no measurement errors occur, and that no sample tree is 
missed. The former two are equally (in)valid for both the full and the truncated ACS, but the likelihood of unobserved sample trees (which are a source of bias) is practically reduced to zero which resulted in a small but notable increase $(\sim 1.3 \%)$ in the overall standing stock estimate. This increase of the estimate is not an overestimation but a result of the elimination of a bias that caused underestimation. This effect was already predicted by Schieler (1997) who attributed the overlooking (mainly, not exclusively) to difficult terrain and/or dense undergrowth. The increased share of stock of trees with $\mathrm{DBH} \geq 60 \mathrm{~cm}$ in the truncated sample (see Table 3) further supports the theory that the effect is due to overlooked sample trees.

There is only a small increase in stock estimates for even smaller plots, and several plot attributes are measured on $300 \mathrm{~m}^{2}$. Furthermore, the truncation facilitates or even enables the establishment of plots in difficult terrain, leading to more information about remote areas. So limiting the plot to this size is the best option for the Austrian NFI. This new plot design follows the advice of Stage and Rennie (1994). They suggest "designs that combine fixed-radius sampling rules for the smallest and largest dbh classes with variable-radius rules for intermediate dbh classes'. Trees with DBH from $5 \mathrm{~cm}$ to $10.4 \mathrm{~cm}$ have been surveyed on small fixed-radius plots (Gabler and Schadauer 2008) since 1981. This is not changed and thus is not in the scope of this article.

When introducing the truncation of the ACS into the NFI, there are two diametrical effects concerning trees with $\mathrm{DBH} \geq$ $39.1 \mathrm{~cm}$. Obviously, any sample tree with a distance larger than $9.77 \mathrm{~m}$ is removed from the sample. All remaining trees with $\mathrm{DBH} \geq 39.1 \mathrm{~cm}$ are no longer in an ACS but instead on a fixed-radius plot with $300 \mathrm{~m}^{2}$. So they are scaled up to a per hectare value with a larger factor than if they were still ACS trees. On average, this makes up for the lost sample trees in the stock estimate. So the regular ACS plot turns into a combination of a truncated ACS plot and a fixed-radius circular plot with the same centre point.

Another perspective is that the sample trees are split into two groups at $\mathrm{DBH}=39.1 \mathrm{~cm}$ and only the smaller trees are ACS trees. For this group, the ACS can be considered to be untruncated because any sample tree big enough to fall into the ACS at a distance above $9.77 \mathrm{~m}$ is so big (DBH at least $39.1 \mathrm{~cm}$ ) that it falls into the other group which is surveyed on the fixed-radius plot. So there is no selection bias for the ACS part of the plot, and it can be viewed as regular ACS on a subsample of the trees.

Both being point sampling methods, the ACS method and fixed-radius plot are unbiased (Bitterlich 1948; Palley and Horwitz 1961; Loetsch et al. 1973), in this case for their respective group. Consequently, the combination of both is unbiased as well (Packard and Radtke 2007), and with a sufficiently large sample, the results of the combined method are expected to be the same as with simple ACS, except for the abovementioned bias due to missed trees.

For some rare tree species, random effects are visible because due to the small sample, the exclusion of a single tree can make a lot of difference and even reverse trends observed on the national level. This effect can be seen in the wide dispersion of the ' + ' - symbols in Fig. 7.

Angle count sampling is sampling proportional to size which means that larger objects are more likely to be sampled. The marginal circle of a tree (Bitterlich 1984) is the area in which the centre of the angle count sample must be in order to include that tree in the sample. The radius of the marginal circle is linearly proportional to the tree's diameter.

The marginal circles of the trees appear naturally in Fig. 2 because the tree represents a certain stock per ha (a certain brightness) if the plot centre is within the marginal circle and zero otherwise. The estimate for the stock at any given point is the sum of the stocks per ha (the overlapping of circles) of all trees for which that point is within the marginal circle. If two points are within the identical marginal circles, they also have the same stock estimate (brightness), and thus the circles become visible. In the figure for the truncated ACS, many circles have a radius of $9.77 \mathrm{~m}$ because the truncation introduces this maximum diameter.

As the formula for the area of a circle contains the square of the radius, a tree with a double diameter has a marginal circle of four times the area. The marginal circle is a measure for the probability that a tree is included in the sample. The truncation of the ACS reduces the marginal circle to a maximum of $300 \mathrm{~m}^{2}$. Trees with a larger marginal circle are quadratically more strongly affected. For example, while there is the same number of trees with $\mathrm{DBH}=39 \mathrm{~cm}$ (untruncated marginal circle $298.6 \mathrm{~m}^{2}$, unchanged), only about a quarter of the trees with $\mathrm{DBH}=78 \mathrm{~cm}$ (untruncated marginal circle $1194.6 \mathrm{~m}^{2}$, reduced to $300 \mathrm{~m}^{2}$ ) remain in the sample.

In practice these ratios are largely confirmed. In the most recent completed Austrian NFI (NFI 7), 957 of the 93,609 trees had a $\mathrm{DBH} \geq 78 \mathrm{~cm}$. Two hundred seventeen $(22.7 \%)$ of these were at a distance of $9.77 \mathrm{~m}$ or less from the plot centre. Because we are counting trees of this size and above, the remaining trees have to be fewer than $25 \%$. Consequently, there are higher uncertainties associated with results and statements about trees with large DBH, but there is no bias introduced because the method is still random point sampling.

The altered sampling method entails a changed training data set for the models of the upper diameter which is needed for stem volume estimates. But it turned out that all versions (full sample, truncated sample, separate model for trees above $60 \mathrm{~cm} \mathrm{DBH}$ ) resulted in very similar estimates for standing stock.

Also the different data distributions within the sample had only a small effect. The deviations on a single tree level occur for values greater than $65 \mathrm{~cm}$ which is a 
range where only few training data points are available. Only a small number of trees are strongly affected. The small change in overall stock is likely due to the fact that the Austrian forests are dominated by a few species for which sufficient data is available also in the truncated sample. For very rare species, the models of spruce or beech are used, and for the species in between, the selection of trees on which the upper diameter is measured has been adapted to ensure a sufficiently large sample. The presented differences stem purely from the NFI 7 data set, where the additional measurements of the upper diameter are not included. So the actual differences can be expected to be even smaller at the end of the current NFI cycle in 2021.

The unusual results on single tree level for some large trees when using a separate model for trees with $\mathrm{DBH} \geq 60 \mathrm{~cm}$ are undesirable. They can probably be attributed to the irregular shapes of the large trees but also to the small training data set for the upper diameter models. It is clear that the separate models provide no benefit and should not be employed.

\section{Conclusion}

The direct effects of the truncation are a different, higher stock estimate and a higher uncertainty of the new sampling method (Fig. 6 and Fig. 4). The field work is facilitated and reduced because there are no more sample trees that are far from the plot centre. It also means that fewer training data for the model for the upper diameter are available. Additionally, the sample is not reduced uniformly, but the reduction occurs only in the more sparsely populated areas of large DBH. Both these effects are partially mitigated by an adapted sample tree selection for upper diameter measurements, and the effects of this change are very small. From an NFI perspective, no major adaptations of the Austrian NFI are required in the course of this method change, and it combines the advantages of ACS and fixed-radius plots.

Acknowledgements We thank our field work crews for collecting the valuable data used in this study.

Funding information This study was funded by the Austrian ministry for sustainability and tourism.

Data availability The datasets generated and/or analysed during the current study are available from the corresponding author on reasonable request, where necessary in aggregated form.

\section{Compliance with ethical standards}

Conflict of interest The authors declare that they have no conflict of interest.
Open Access This article is licensed under a Creative Commons Attribution 4.0 International License, which permits use, sharing, adaptation, distribution and reproduction in any medium or format, as long as you give appropriate credit to the original author(s) and the source, provide a link to the Creative Commons licence, and indicate if changes were made. The images or other third party material in this article are included in the article's Creative Commons licence, unless indicated otherwise in a credit line to the material. If material is not included in the article's Creative Commons licence and your intended use is not permitted by statutory regulation or exceeds the permitted use, you will need to obtain permission directly from the copyright holder. To view a copy of this licence, visit http://creativecommons.org/licenses/by/4.0/.

\section{References}

Berger A, Gschwantner T, McRoberts ME, Schadauer K (2014) Effects of measurement errors on individual tree stem volume estimates for the Austrian National Forest Inventory. For Sci 60(1):14-24. https:// doi.org/10.5849/forsci.12-164

Bitterlich W (1948) Die Winkelzählprobe. Allg Forst u Holzwirtsch Ztg 59:4-5

Bitterlich W (1984) The relascope idea. Commonwealth Agricultural Bureaux, Norwich

Braun R (1969) Österreichische Forstinventur, Methodik der Auswertung und Standardfehler-Berechnung. Mitt. Forstl. Bundes-Vers.anst. Wien 84. Österreichischer Agrarverlag, Wien, Austria, p 60

Gabler K, Schadauer K (2008) Methods of the Austrian Forest inventory 2000/02 - origins, approaches, design, sampling, data models, evaluation and calculation of standard error. BFW-Berichte, Vienna, $p$ 142

Grosenbaugh LR (1952) Plotless timber estimates: new-fast-easy. J For 50:32-37. https://doi.org/10.1093/jof/50.1.32

Gschwantner T, Gabler K, Schadauer K, Weiss P (2010) Individual country reports: Austria. In: Tomppo E et al (eds) National Forest Inventories - pathways for common reporting. Springer, Berlin

Gschwantner T, Lanz A, Vidal C, Bosela M, Di Cosmo L, Fridman J, Gasparini P, Kuliešis A, Tomter S, Schadauer K (2016) Comparison of methods used in European National Forest Inventories for the estimation of volume increment: towards harmonisation. Ann For Sci 73:807-821. https://doi.org/10.1007/s13595-016-0554-5

Hollaus M, Wagner W, Maier B, Schadauer K (2007) Airborne laser scanning of Forest stem volume in a mountainous environment. Sensors 7:1559-1577

Hollaus M, Wagner W, Schadauer K, Maier B, Gabler K (2009) Growing stock estimation for alpine forests in Austria: a robust lidar-based approach. Can J For Res 39:1387-1400. https://doi.org/10.1139/ X09-042

Kilian W, Müller F, Starlinger F (1994) Die forstlichen Wuchsgebiete Österreichs. Eine Naturraumgliederung nach waldökologischen Gesichtspunkten. FBVA-Berichte Nr. 82, Schriftenreihe der Forstlichen Bundesversuchsanstalt Wien

Loetsch F, Zöhrer F, Haller KE (1973) Forest inventory, volume 2. BLV, Munich

Maltamo M, Korhonen KT, Packalén P, Mehtätalo L, Suvanto A (2007) Testing the usability of truncated angle count sample plots as ground truth in airborne laser scanning-based forest inventories. Forestry 80:73-81. https://doi.org/10.1093/forestry/cpl045

Næsset E, Gobakken T, Bollandsås OM, Gregoire TG, Nelson R, Ståhl G (2013) Comparison of precision of biomass estimates in regional field sample surveys and airborne LiDAR-assisted surveys in Hedmark County, Norway. Remote Sens 130:108-120. https://doi. org/10.1016/j.rse.2012.11.010 
Packard KC, Radtke PJ (2007) Forest sampling combining fixed- and variable-radius sample plots. Can J For Res 37:1460-1471

Palley MN, Horwitz LG (1961) Properties of some random and systematic point sampling estimators. For Sci 7(1):52-65. https://doi.org/ 10.1093/forestscience/7.1.52

Pollanschütz J (1974) Formzahlfunktionen der Hauptbaumarten Österreichs. Allg Forstztg 85:341-343

Polley H, Schmitz F, Hennig P, Kroiher F (2010) Individual country reports: Germany. In: Tomppo E et al (eds) National Forest Inventories - pathways for common reporting. Springer, Berlin

Schieler K (1988) Methodische Fragen in Zusammenhang mit der Österreichischen Forstinventur. Diploma thesis. University of Natural Resources and Life Sciences, Vienna

Schieler K (1997) Methode der Zuwachsberechnung der Österreichischen Waldinventur. Dissertation. University of Natural Resources and Life Sciences, Vienna

Scrinzi G, Clementel F, Floris A (2015) Angle count sampling reliability as ground truth for area-based LiDAR applications in forest inventories. Can J For Res 45:506-514. https://doi.org/10.1139/cjfr-20140408
Stage AR, Rennie JC (1994) Fixed-radius plots or variable-radius plots? Designing effective inventory. J For 92:20-24. https://doi.org/10. 1093/jof/92.12.20

Tomppo E, Tuomainen T (2010) Individual country reports: Finland. In: Tomppo E et al (eds) National forest inventories - pathways for common reporting. Springer, Berlin

Tomppo E, Heikkinen J, Henttonen HM, Ihalainen A, Katila M, Mäkelä H, Tuomainen T, Vainikainen N (2011) Designing and conducting a forest inventory - case: 9th National Forest Inventory of Finland. Managing Forest ecosystems, vol 22. Springer, Dordrecht

Tomppo E, Kuusinen N, Mäkisara K, Katila M, McRoberts RE (2016) Effects of field plot configurations on the uncertainties of ALSassisted forest resource estimates. Scand J For Res 32:488-500. https://doi.org/10.1080/02827581.2016.1259425

Vauhkonen J, Maltamo M, McRoberts RE, Næsset E (2014) Introduction to forestry applications of airborne laser scanning. In: Maltamo M, Næsset E, Vauhkonen J (eds) Forestry applications of airborne laser scanning. Managing Forest ecosystems, vol 27. Springer, Dordrecht

Publisher's note Springer Nature remains neutral with regard to jurisdictional claims in published maps and institutional affiliations. 